PACS:42.40.Eq, 42.70.Ln

\title{
Recording the high efficient diffraction gratings by using He-Cd laser
}

\author{
S.A. Kostyukevych ${ }^{1 *}$, A.N. Morozovska ${ }^{1 * *}$, V.I. Minko ${ }^{1}$, P.E. Shepeliavyi ${ }^{1}$, A.A. Kudryavtsev $^{1}$, V.M. Rubish ${ }^{2}$, \\ V.V. Rubish ${ }^{2}$, I.V. Tverdokhleb ${ }^{2}$, A.S. Kostiukevych ${ }^{1,3}$, S.V. Dyrda ${ }^{4}$ \\ 1 V. Lashkaryov Institute of Semiconductor Physics, NAS of Ukraine, \\ 41, prospect Nauky,03028Kiev,Ukraine,*sekret@spie.org.ua,**morozo@i.com.ua \\ 2 Uzhgorod National University, 54, Voloshina str., 88000 Uzhgorod, Ukraine \\ 3 National Agricultural University, 03028 Kiev, Ukraine \\ 4 Taras Shevchenko Kiev National University, 2, prospect Glushkova, 03127 Kiev, Ukraine
}

\begin{abstract}
High efficient holographic diffraction gratings with spatial frequencies from 600 to $3600 \mathrm{~mm}^{-1}$ have been recorded using $\mathrm{As}_{40} \mathrm{~S}_{60-\mathrm{x}} \mathrm{Se}_{\mathrm{x}}(\mathrm{x}=0,10,20)$ photoresist layers and He-Cd laser operating at the wavelength $\lambda=440 \mathrm{~nm}$. The investigation of the grating relief made by atomic force microscopy revealed that $\mathrm{As}_{40} \mathrm{~S}_{60-\mathrm{x}} \mathrm{Se}_{\mathrm{x}}$ resists allows one to record grating originals with profiles of various heights depending on the resist chemical composition, its etching and exposure times. We obtained typical spectral and angular dependences of the first order diffraction efficiency for the grating with the high modulation depth and groove profile close to the sinusoidal one. Comparing the recorded gratings with different spatial frequencies, exposure and etching times, we determined optimal recording conditions (exposure and etching times) in order to obtain gratings with the high diffraction efficiency.
\end{abstract}

Keywords: inorganic photoresist, selective etching, holographic diffraction gratings.

Manuscript received 06.10.04; accepted for publication 16.12.04.

\section{Introduction}

The prospective way for manufacturing holographic diffraction gratings (HDG) with the high diffraction efficiency [1] is using the chalcogenide resist layers [2]. The simplicity of sputtering, stability of sensitometric characteristics, high quality of selective enchants allows one to simplify the technology to produce high quality HDGs. This has been proved in papers [3-9], where the formation of HDG using As-S-Se layers were reported.

The resist layers $\mathrm{As}_{40} \mathrm{~S}_{60-\mathrm{x}} \mathrm{Se}_{\mathrm{x}}(\mathrm{x}=0,10,20)$ possess the most stable properties and best exploitation characteristics. The high efficient HDGs with spatial frequencies 600 up to $3600 \mathrm{~mm}^{-1}$ recorded on these layers were reported in [10-11]. The HDG relief investigation by atomic force microscopy (AFM) revealed that resists $\mathrm{As}_{40} \mathrm{~S}_{60-\mathrm{x}} \mathrm{Se}_{\mathrm{x}}$ allow to record HDG originals with various height profiles depending on the composition $\mathrm{x}$ and exposure time (Fig. 1). Different kinds of holographic protective elements have been manufactured using laser, and electron-beam lithography as well as their properties have been studied. High quality nickel matrices and holographic protective elements (that include optical, digital holograms and submicron text) for documents and goods protection in Ukraine were obtained. Thus, resists with the composition $\mathrm{As}_{40} \mathrm{~S}_{60-\mathrm{x}} \mathrm{Se}_{\mathrm{x}}$ are undoubtedly of practical interest as recording media for optical elements $[12,13]$.
However recording the high efficient HDG by using He$\mathrm{Cd}$ laser was not studied earlier because of the relatively small coherence length of such lasers. In particular recording of the HDG on wavelengths of $\mathrm{He}-\mathrm{Ne} \mathrm{Ta} \mathrm{Ar}$ lasers was reported in papers [3-6], but the later takes place under the significantly lower resist photosensitivity in comparison with recording by using He-Cd laser, and thus demands higher operating laser powers. Having the modern types of He-Cd lasers, it is possible to record high efficient HDGs on $\mathrm{As}_{40} \mathrm{~S}_{60-\mathrm{x}} \mathrm{Se}_{\mathrm{x}}$ layers at essentially lower energy consumption, than doing the same by using $\mathrm{He}-\mathrm{Ne}$ or Ar lasers.

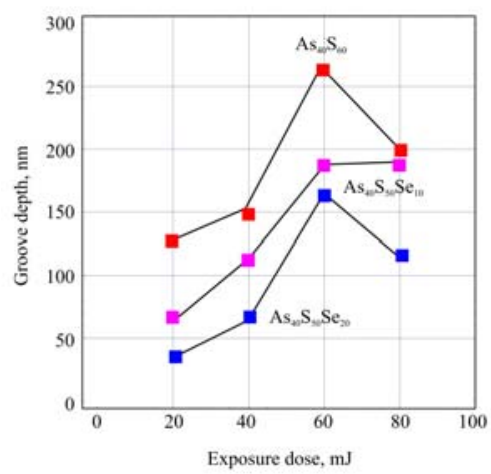

Fig. 1. Dependence of the groove depth on the exposure for the HDG with the spatial frequency $1200 \mathrm{~mm}^{-1}$ (HDG recorded at $\lambda=441 \mathrm{~nm}$, negative etching, etching time corresponds to an optimum relief). 


\section{Experimental description}

Holographic recording a diffraction grating is based on registration of the interference pattern created by two coherent beams inside the photosensitive medium. He$\mathrm{Cd}$ laser was operating at $\lambda=441 \mathrm{~nm}$. The photosensitive system was made by deposition of chalcogenide $\mathrm{As}_{40} \mathrm{~S}_{60-\mathrm{x}} \mathrm{Se}_{\mathrm{x}}(\mathrm{x}=0,10,20)$ layers with the thickness $1 \mu \mathrm{m}$ on polished glass substrates by thermal evaporation in vacuum. After exposure, the layer treatment was made by organic selective enchant based on amines [9], in which the selective dissolution of nonexposed regions of $\mathrm{As}_{2} \mathrm{~S}_{3}$ layers (negative etching) took place and symmetrical relief was obtained. The HDG height and profile are determined not only by laser beam intensity distribution inside the layer under exposure, but also by the etching time. Then the thin layer of high efficient reflective coating was deposited (e.g. Al layer). The surface topography and groove shape have been investigated by AFM NanoScope IIIa (Scanning Probe Microscope made by Digital Instruments).

\section{HDG on resist layers of $\mathrm{As}_{2} \mathrm{~S}_{3}$}

AFM investigation revealed that the characteristic feature of HDG with the spatial frequency $2200-$ $3400 \mathrm{~mm}^{-1}$ recorded in resist $\mathrm{As}_{2} \mathrm{~S}_{3}$ layers is their relatively high quality of groove profile (see Fig. 2). In particular, we obtained HDG with almost sinusoidal groove profile and high modulation depth $20 \leq m \leq 40 \%$ (see Fig. 3) depending on the postexposure treatment (namely, etching time) and chemical composition, which provided their high diffraction efficiency 60 to $90 \%$. We obtained that at the defined etchant selectivity and exposure time value the groove depth $h$ mainly depends on the etching time (see Fig. 4).

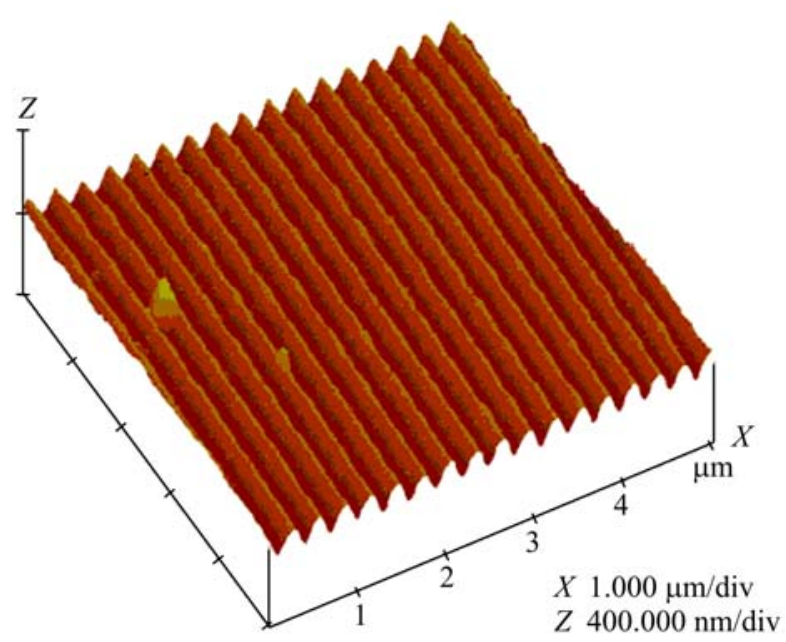

Fig. 2. Surface of the holographic diffraction grating with the spatial frequency $3600 \mathrm{~mm}^{-1}$ etched for $90 \mathrm{~s}$.
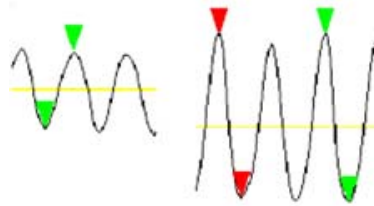

$t=30 \mathrm{sec}$
$h=90 \mathrm{~nm}$
$m=20 \%$

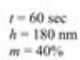

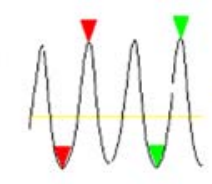

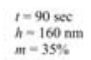

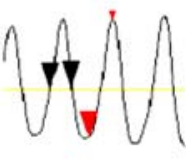

$t=120 \mathrm{sec}$
$h=140 \mathrm{~nm}$
$m=31 \%$
Fig. 3a. Relief of the HDG with the spatial frequency $2200 \mathrm{~mm}^{-1}$ for various etching times $t$ (period $d=454.5 \mathrm{~nm}$, groove depth $h$, modulation depth $m=h / d$ ).

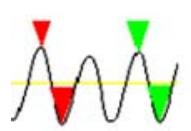

$t=60 \mathrm{sec}$
$h=60 \mathrm{~nm}$
$m=20 \%$
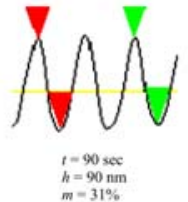
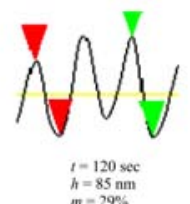
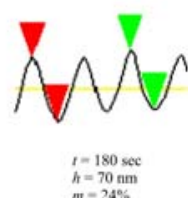

Fig. 3b. Relief of the HDG with the spatial frequency $3400 \mathrm{~mm}^{-1}$ for various etching times $t$ (period $d=294 \mathrm{~nm}$, groove depth $h$, modulation depth $m=h / d$ ).
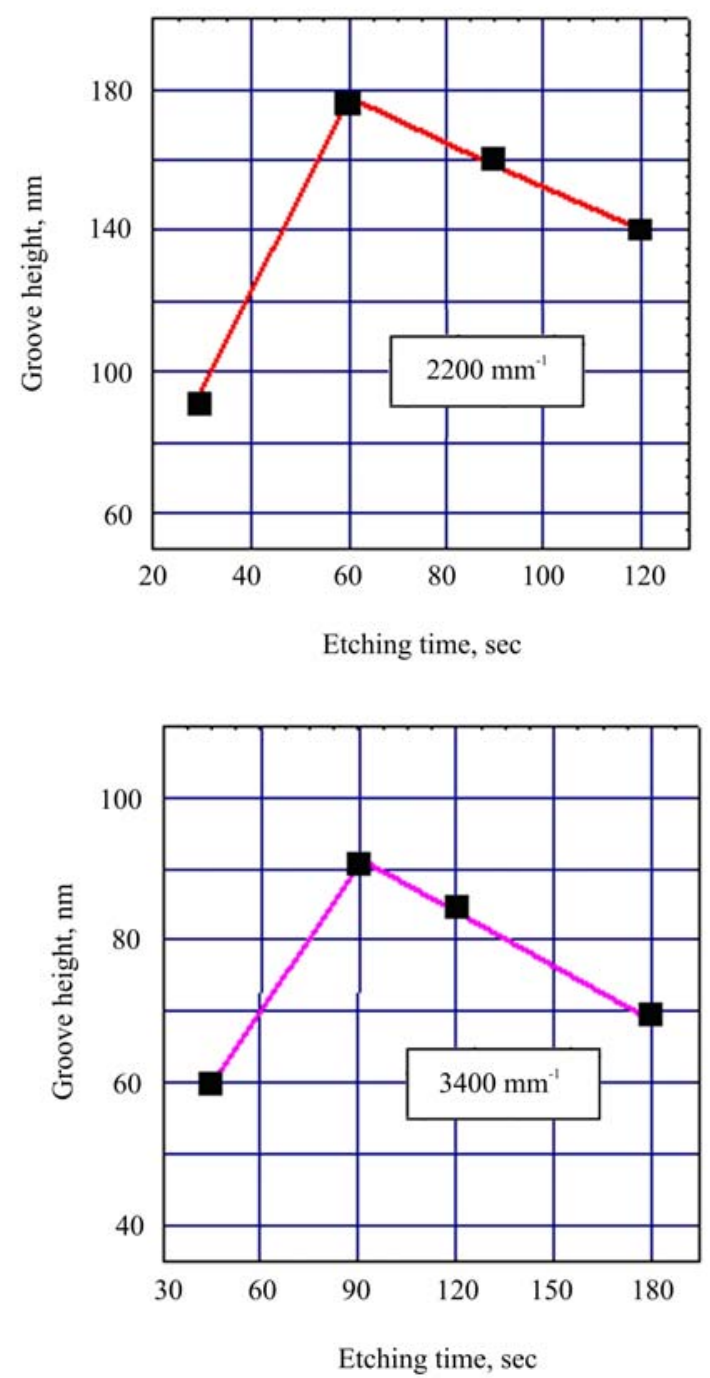

Fig. 4. Dependence of the groove depth for HDG with the spatial frequency 2200 and $3400 \mathrm{~mm}^{-1}$ on the time of negative etching for exposure $H=90 \mathrm{~mJ} / \mathrm{cm}^{2}$ (Hereinafter $\mathrm{HDG}$ recorded at $\lambda=441 \mathrm{~nm}, \mathrm{As}_{2} \mathrm{~S}_{3}$ ). 
Let us underline, that the harmonic (sinusoidal) shape of HDG profile permits us to provide serial replication, exact original HDG copying and obtain HDG copies with the identical spectral and angular diffraction efficiency $\eta$. Both the shape and height of the groove profile determine spectral and angular diffraction efficiency dependences.

\section{Spectral and angular diffraction efficiency dependences}

The spectral first order diffraction efficiency $\eta(\lambda)$ was measured using the conventional Littrow scheme [1] in the wavelength region $\lambda=(400-800) \mathrm{nm}$.

Figs 5-6 demonstrate spectral and angular dependences of the diffraction efficiency $\eta$ of HDG recorded in $\mathrm{As}_{2} \mathrm{~S}_{3}$ layers at various etching times $t$ (measurements were carried out in transverse $(s)$ and parallel $(p)$ polarizations of incident light, the exposure value was $H=90 \mathrm{~mJ} / \mathrm{cm}^{2}$ ). At small etching times the height of grooves is small enough, and thus the modulation depth $m$ is also small. Therefore, the grating etched for about $30 \mathrm{~s}$ or less demonstrates low values of the diffraction efficiency in the most part of the studied spectral region. At long etching times $(\sim 120 \mathrm{~s})$ groove profile is over-etched and so transforms in such a way that again becomes shallower. The optimal situation corresponds to the intermediate etching times between 60 and $90 \mathrm{~s}$. This opens the possibility to obtain HDG with the high diffraction efficiency at etching times 60 , $90 \mathrm{~s}$.

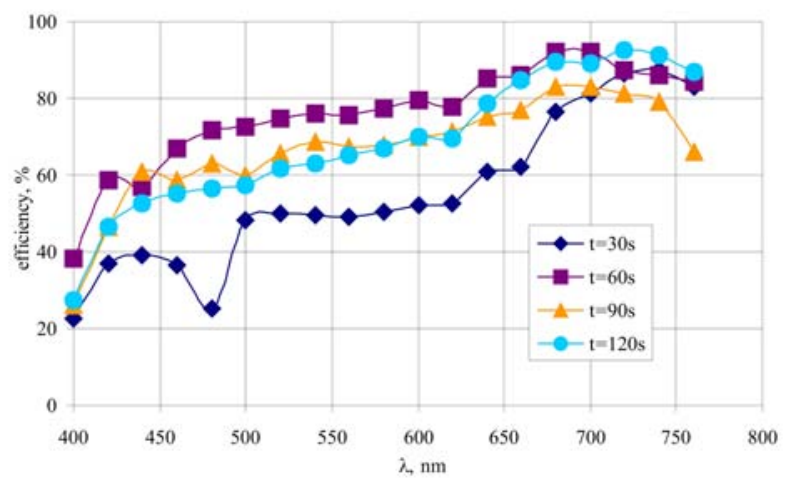

Fig. 5a. Spectral dependences of the diffraction efficiency $\eta(\lambda)$ for HDG with the spatial frequency $2200 \mathrm{~mm}^{-1}$ for perpendicular $s$-polarization of light and various etching times $t$ (in seconds).

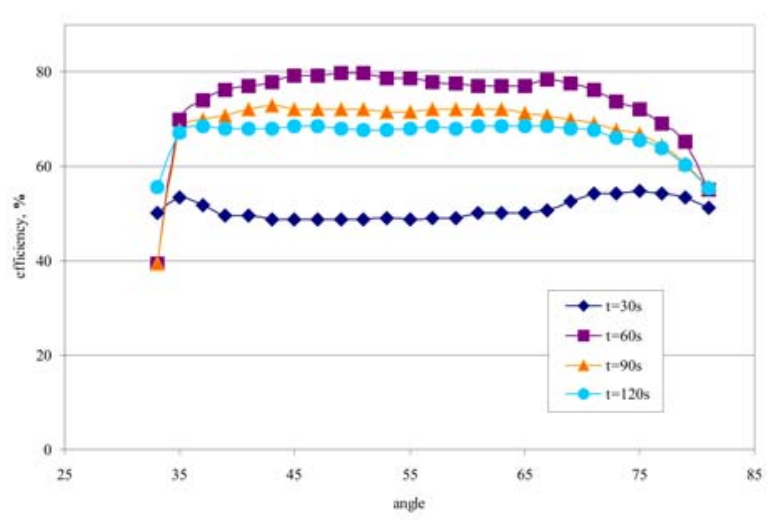

Fig. 5b. Angular dependences of the diffraction efficiency $\eta(\varphi)$ for HDG with the spatial frequency $2200 \mathrm{~mm}^{-1}$ for $s$ polarization and various etching times $t$ (in seconds).

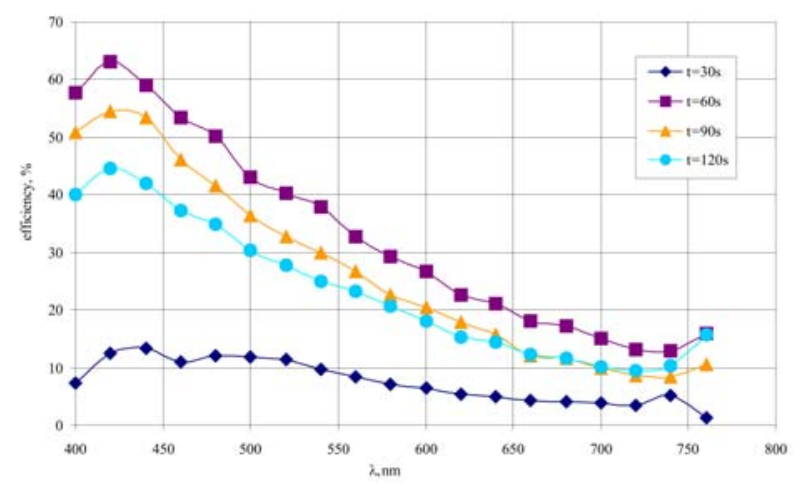

Fig. 5c. Spectral dependences of the diffraction efficiency $\eta(\lambda)$ for the HDG with the spatial frequency $2200 \mathrm{~mm}^{-1}$, for parallel $p$-polarization of light and various etching times $t$ (in seconds).

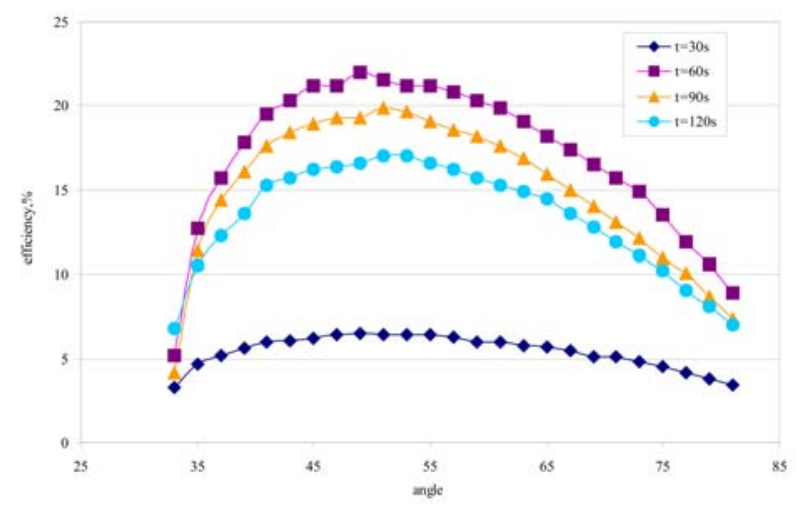

Fig. 5d. Angular dependences of the diffraction efficiency $\eta(\varphi)$ for the HDG with the period $2200 \mathrm{~mm}^{-1}$, p-polarization and various etching times $t$ (in seconds). 


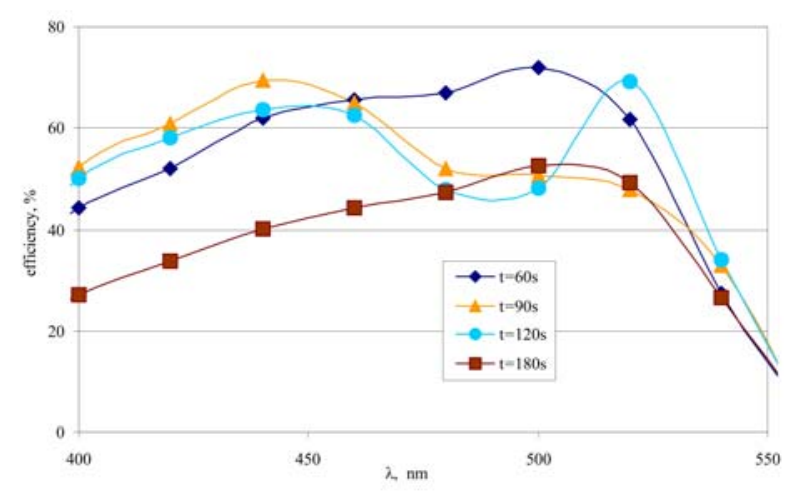

Fig. 6a. Spectral dependences of the diffraction efficiency $\eta(\lambda)$ for HDG with the spatial frequency $3400 \mathrm{~mm}^{-1}, s$-polarization of light and various etching times $t$ (in seconds).

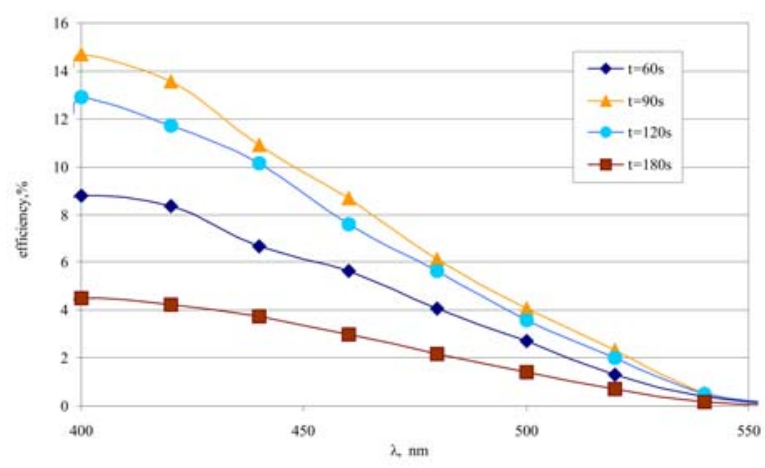

Fig. 6b. Spectral dependences of the diffraction efficiency $\eta(\lambda)$ for HDG with the spatial frequency $3400 \mathrm{~mm}^{-1}$, $p$-polarization of light and various etching times $t$ (in seconds).

The spectral $(a, b)$ and angular $(c, d)$ dependences of the HDG diffraction efficiency recorded at different exposures $H=(50-170) \mathrm{mJ} / \mathrm{cm}^{2}$ and optimal etching times $t=(60-90) \mathrm{s}$ are presented in Figs 7, 8. At small exposures $H<40 \mathrm{~mJ} / \mathrm{cm}^{2}$, the modulation depth is relatively small. This effect causes low values of the diffraction efficiency of HDG recorded at $H<40 \mathrm{~mJ} / \mathrm{cm}^{2}$ in the most part of the studied spectral region. Under further increasing the exposure, the diffraction efficiency also increases. The highest diffraction efficiency values have been obtained at intermediate exposure values $H=(70-100) \mathrm{mJ} / \mathrm{cm}^{2}$ (see Fig. 7). Concerning the changes in the HDG profile, the general rule is valid: under increasing exposure the saturation of tops, narrowing and deepening of grooves are observed. At high exposures $H=(110-200) \mathrm{mJ} / \mathrm{cm}^{2}$, the sinusoidal groove profile is subjected to strong changes, namely, it transforms into the almost cycloidal one with wide tops and narrow grooves. The angular dependences $\eta(\varphi)$ of HDG recorded at further increasing exposure $H=(110-117) \mathrm{mJ} / \mathrm{cm}^{2}$ are depicted in Fig. 8. The main differences between the dependences shown in Figs 8 and those presented in Figs 7c,d can be explained by the deviation of the HDG profile from the sinusoidal one with increasing exposure.

The spectral dependence of the HDG diffraction efficiency $\eta(\lambda)$ for the spatial frequency $2200 \mathrm{~mm}^{-1}$ on the etching time at several wavelengths $(\lambda=400-$ $760 \mathrm{~nm}$ ) measured at $s$-polarization is presented in Fig. 9. We choose the optimal exposure value $H \approx 90 \mathrm{~mJ} / \mathrm{cm}^{2}$. Diffraction efficiency increases with $\lambda$ increasing up to $\lambda \approx 720 \mathrm{~nm}$ in all the region of etching times from 30 to $120 \mathrm{~s}$. It is clear from the figure that at $\lambda=(400-700) \mathrm{nm}$ HDGs demonstrate the maximum diffraction efficiency values at etching times close to one minute. At first glance, it is reasonable to increase the etching time up to two minutes only for using HDG in the infrared spectral region $\lambda>700 \mathrm{~nm}$. But let us to remind once more that at high etching times the original groove profile quality is reduced (the modulation depth is reduced, inharmonic changes appeared), and thus problems with HDG replication could arise.

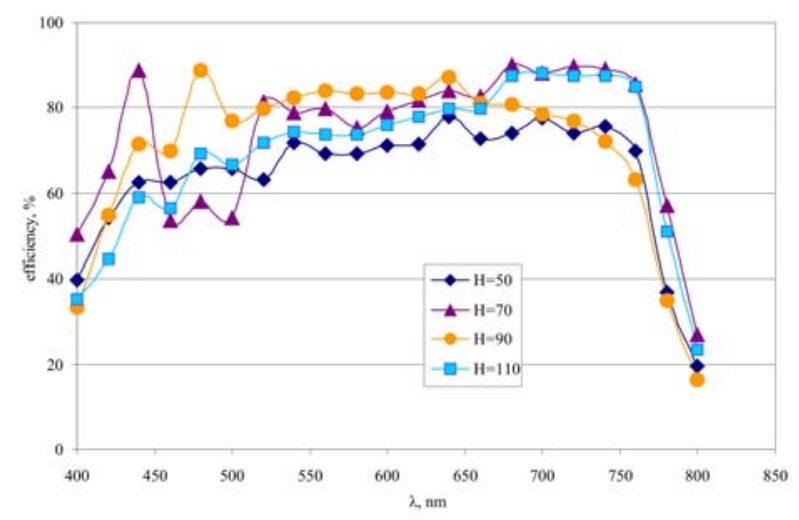

Fig. 7a. Spectral dependences of the diffraction efficiency $\eta(\lambda)$ for HDG with the spatial frequency $2200 \mathrm{~mm}^{-1}, s$-polarization of light and various exposures $H\left(\right.$ in $\left.\mathrm{mJ} / \mathrm{cm}^{2}\right)$.

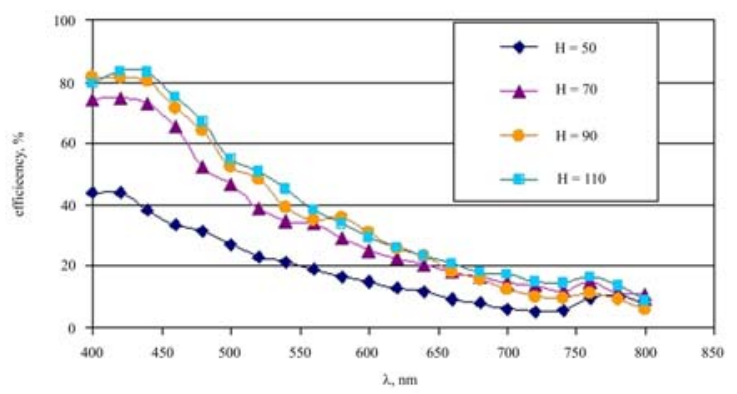

Fig. 7b. Spectral dependences of the diffraction efficiency $\eta(\lambda)$ for HDG with the spatial frequency $2200 \mathrm{~mm}^{-1}$, $p$-polarization of light and various exposures $H\left(\right.$ in $\left.\mathrm{mJ} / \mathrm{cm}^{2}\right)$. 


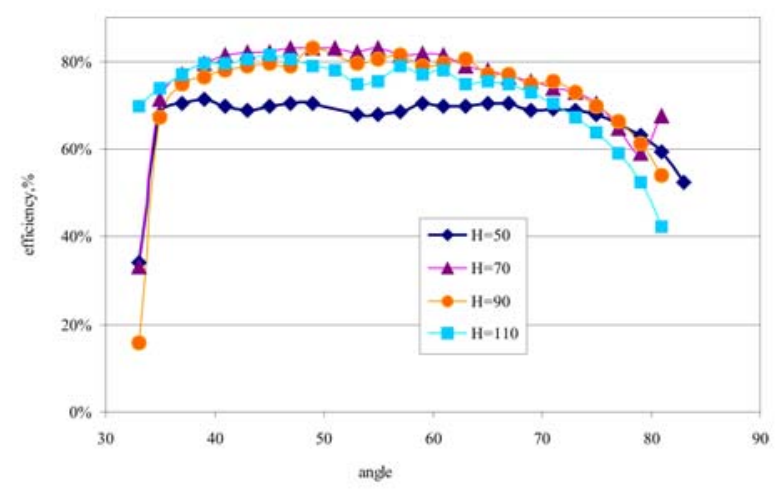

Fig. 7c Angular dependences of the diffraction efficiency $\eta(\varphi)$ for the HDG with the spatial frequency $2200 \mathrm{~mm}^{-1}, s$ polarization and various exposures $H$ ( in $\mathrm{mJ} / \mathrm{cm}^{2}$ ).

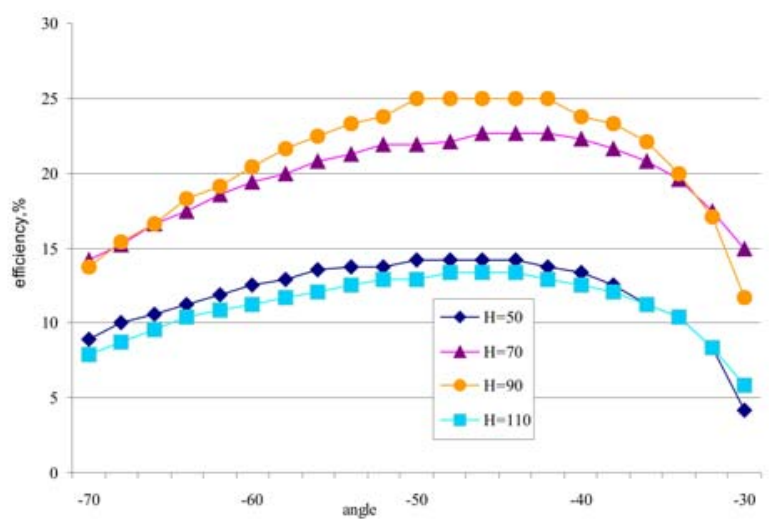

Fig. 7d Angular dependences of the diffraction efficiency $\eta(\varphi)$ for the HDG with the spatial frequency $2200 \mathrm{~mm}^{-1}, p$ polarization and various exposures $H\left(\right.$ in $\mathrm{mJ} / \mathrm{cm}^{2}$ ).

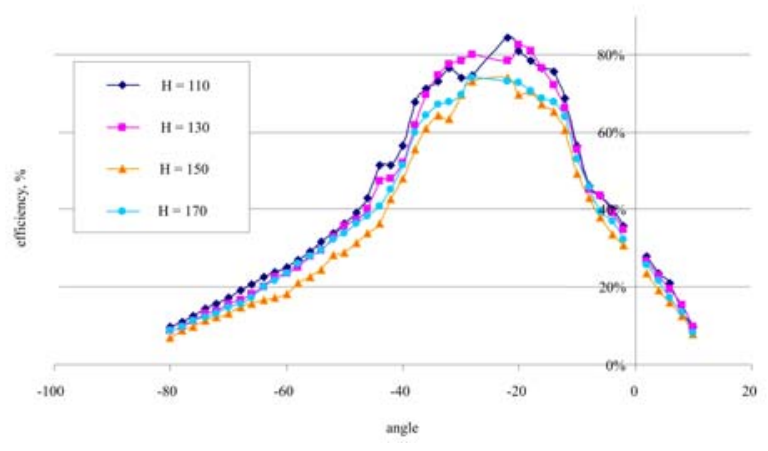

Fig. 8a Angular dependences of the diffraction efficiency $\eta(\varphi)$ for the HDG with the spatial frequency $2200 \mathrm{~mm}^{-1}, p$ polarization and increased exposures $H>110 \mathrm{~mJ} / \mathrm{cm}^{2}$.

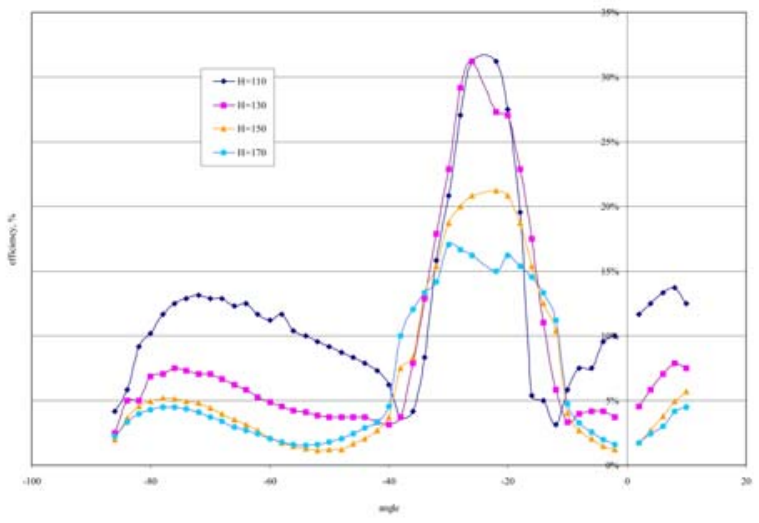

Fig. 8b Angular dependences of the diffraction efficiency $\eta(\varphi)$ for the HDG with the spatial frequency $2200 \mathrm{~mm}^{-1}, s$ polarization and increased exposures $H>110 \mathrm{~mJ} / \mathrm{cm}^{2}$.

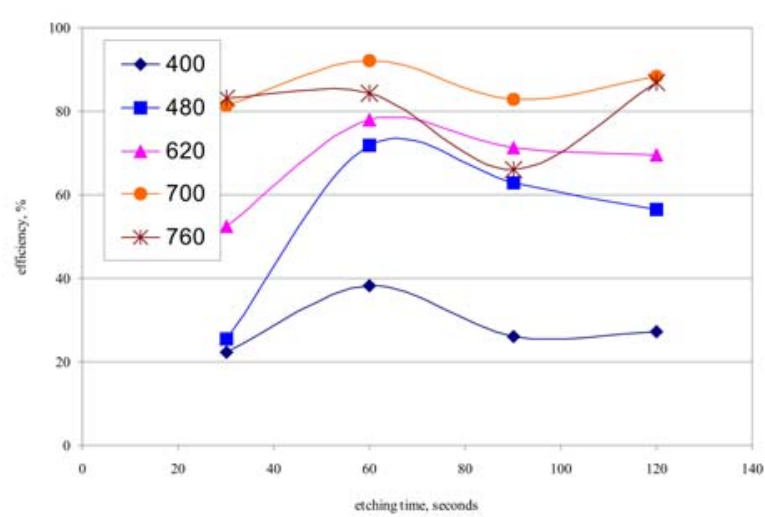

Fig. 9. Dependences of the diffraction efficiency $\eta$ for the HDGs with the spatial frequency $2200 \mathrm{~mm}^{-1}$ on the etching time for various wavelength of incident light $(\lambda=400,480$, $620,700,760 \mathrm{~nm}$ ); s-polarization, exposure $H \sim 90 \mathrm{~mJ} / \mathrm{cm}^{2}$.

\section{Discussion}

We obtained typical spectral and angular dependences of the first order diffraction efficiency $\eta$ for the grating with the high modulation depth $20 \leq m \leq 40 \%$ and groove profile close to the sinusoidal one [14].

Spectral dependences values for $s$-polarization reveal some oscillation behavior at $\lambda=(420-480) \mathrm{nm}$ and maximum at $\lambda=(700-750) \mathrm{nm}$ (see. Figs 5a, 7a). Such behavior of $\eta(\lambda)$ for HDG with the period $d=454.5 \mathrm{~nm}$ (spatial frequency $2200 \mathrm{~mm}^{-1}$ ) for $s$ polarization correlates with theoretical calculations at $\lambda / d \sim(0.7-1.1)$ (minimum) and $\lambda / d \sim(1.55-1.80)$ (maximum) (compare with the Figs $9-13,14$ from [1]). Angular dependences of diffraction efficiency $\eta(\varphi)$ for $s$-polarization have a conventional view of wide tops at 
$\varphi=(35-85)^{\circ}$ with small oscillations (see Figs $5 b, 7 c$ ). The spectral efficiency values of HDG with $d=294 \mathrm{~nm} \quad\left(3400 \mathrm{~mm}^{-1}\right)$ drastically decreases at $\lambda \geq 550 \mathrm{~nm}$ (see. Fig. 6a for $s$-polarization of incident light) this corresponds to the theoretical calculations in the case $\lambda / d>1.8$.

The spectral diffraction efficiency $\eta(\lambda)$ of HDG with the period $d=454.5 \mathrm{~nm}$ (see Figs $5 \mathrm{c}, 7 \mathrm{~b}$ ) for $p$ polarization of incident light almost monotonically increases under wavelength decreasing, then saturates or has smooth maximum at $\lambda \approx(400-420) \mathrm{nm}$, which correlates with theoretical calculations of such behavior at $\lambda / d \sim(0.7-0.9)$ (compare with Figs $9-13,14$ from [1]). Angular dependences of the diffraction efficiency $\eta(\varphi)$ for $p$-polarization have a typical view of the smooth maximum near $\varphi \approx 50^{\circ}$ (see Figs $5 d, 7 d$ ). The efficiency $\eta(\lambda)$ of HDG with the period $d=294 \mathrm{~nm}$ (see Fig. 6b) monotonically increases with the decreasing of wavelength, which completely corresponds to the theoretical calculations [14] at $\lambda / d \geq 1.3$.

Using Fig. 9, we compared recorded HDG with the spatial frequency $2200 \mathrm{~mm}^{-1}$ at different exposures and etching times and determined the optimal parameters for recording HDGs with the high diffraction efficiency $\eta \approx(70-90) \%$ within the wavelength region $\lambda \sim(500-700) \mathrm{nm}$, namely: etching time $t \sim 60 \mathrm{~s}$, exposure value $H=(90-70) \mathrm{mJ} / \mathrm{cm}^{2}$.

\section{Conclusion}

Comparing the recorded in the inorganic resist layers $\mathrm{As}_{40} \mathrm{~S}_{60-\mathrm{x}} \mathrm{Se}_{\mathrm{x}}(\mathrm{x}=0,10,20)$ HDGs with different spatial frequencies, exposures and etching times, we determined optimal recording conditions (exposure and etching times). Under these conditions it is possible to record gratings with the high diffraction efficiency by using HeCd laser.

\section{References}

1. C. Palmer, Diffractional grating handbook, ed. by E. Loewen, New York (2002).

2. M. Wlchek, A.V. Stronsky, P.E. Shepeliavyi, Multicomponent chalcogenide inorganic resists: properties and application in diffraction optics // Optoelectronics and Semiconductor Technics, Issue 33, p. 137-141 (1998).

3. A.V. Stronsky, The peculiarities of periodic relief recorded in the $\mathrm{As}_{40} \mathrm{~S}_{60}$ layers // Ibid. Issue 32, p. 95-98 (1997).
4. S.A. Kostyukevych, P.E. Shepeliavyi, P.F. Romanenko, I.V. Tverdokhleb, The investigation of production processes of holographic diffraction gratings based on $\mathrm{As}_{2} \mathrm{~S}_{3}$-layers // Zhurn. Tekhn. Fiz. 73, N 1, p. 123-126 (2003).

5. I.Z. Indutniy, S.A. Kostyukevych, V.I. Minko, A.V. Stronsky, P.E. Shepeliavyi, Laser lithography in the layers $\mathrm{As}_{2} \mathrm{~S}_{3} / /$ Optoelectronics and Semiconductor Technics, N 25, p. 52-59 (1993).

6. V.I. Minko, P.E. Shepeliavyi, V.A. Dan'ko, P.F. Romanenko, O.S. Litvin, I.Z. Indutniy, Recording of high efficiency diffraction gratings by $\mathrm{He}-\mathrm{Ne}$ laser // Semiconductor Physics, Quantum Electronics \& Optoelectronics 7, N 1, p. 88-92 (2004).

7. M.D. Michailov, S.B. Mamedov, Dissolution kinetics of $\mathrm{As}_{2} \mathrm{~S}_{3}$ in $\mathrm{Na}_{2} \mathrm{~S}$ and $\mathrm{NaOH}$ solutions // Physics and Chemistry of Glasses 12, N 4, p. 452455 (1986).

8. M.D. Michailov, S.B. Mamedov, S.V. Tsventarnyi, Dissolution kinetics of glassy arsenic sulfide in alkali and amine solutions // J. Non-Crystal. Solids 176, p. 258-262 (1994).

9. Russia, Patent N $2165902 \mathrm{C} 1$, Int.Cl. ${ }^{7} \mathrm{C} 03 \mathrm{C} 15 / 00$, 23/00, The way of negative etchant preparation for resistant layers $\mathrm{As}_{2} \mathrm{~S}_{3}$ // Venger E.F., Kostyukevych S.A., Shepeliavyi P.E., Goltsov Yu.G., Yu.A., Kryuchyn A.A., Petrov V.V. - Publ. 27.04.2001, Bull. N 12 (in Russian).

10. Ukraine, Patent N 36209 C2, Int.Cl. ${ }^{7}$ G03H 1/18, $\mathrm{C} 02 \mathrm{~B} 5 / 32$, The way of diffraction grating manufacturing // Venger E.F., Kostyukevych S.A., Shepeliavyi P.E., Goltsov Yu.G. - Publ. 15.01.2003, Bull. N 1 (in Ukrainian).

11. Russia, Patent N 2165637 C1, Int.Cl. ${ }^{7}$ G03H 1/18, C02B 5/32, The way of holographic diffraction grating manufacturing // Venger E.F., Kostyukevych S.A., Shepeliavyi P.E., Goltsov Yu.G. - Publ. 20.04.2001, Bull. N 11 (in Russian).

12. Ukraine, Declaration patent N 65921 A Int.Cl. ${ }^{7}$ G11B7/26, The way of optical syngalogram preparation // Kostyukevych S.A., Shepeliavyi P.E., Moskalenko N.L., Vishinskaya A.V. - Publ. 15.04.2004, Bull. N 4 (in Ukrainian).

13. S.A. Kostyukevych, Application of chalcogenide vitreous semiconductors in manufacturing holographic protective elements // Proc. SPIE-IS\&T Electronic Imagining 5005, p. 103-109 (2003).

14. E.G. Lowen, Grating efficiency theory as it applies to blazed and holographic gratings // Appl. Opt. 16, p. 2711-2721 (1977). 